\title{
Federalism and individual liberty
}

\section{Mantzavinos}

\begin{abstract}
This paper explores the relationship between federalism and individual liberty. It is shown that a complete treatment of the relationship between federalism and individual liberty should consider two countervailing effects. On the one hand, a federalist structure enhances individual liberty by enlarging the choice set of the citizens. On the other hand, however, a federalist system leads to institutional diversity, a fact that per se leads to higher exit costs, which a citizen must bear if he or she decides to change jurisdictions. This effect on individual liberty is a negative one, since a consequence of every increase in the exit costs is a decrease of individual liberty. The optimum range of diversity of jurisdictions is shown to lie where the two effects counterbalance each other.
\end{abstract}

Keywords Federalism $\cdot$ Individual liberty $\cdot$ Exit costs

\section{JEL Classification $\quad \mathrm{H} 77$}

\section{Introduction}

Federalism as a constitutional structure aims at splitting political power among federal, state and local governments, so that the probability that a single majority can impose its will on all levels of government is ruled out. As Madison put it in his classical formulation: "In a single republic, all the power surrendered by the people is submitted to the administration of a single government; and usurpations are guarded against by a division of the government into distinct and separate departments. In the compound government of America, the power surrendered by the people is first divided between two distinct governments, and then the portion

C. Mantzavinos $(\bowtie)$

Witten/Herdecke University, Alfred Herrhausen Str. 50, 58448 Witten, Germany

e-mail: mantzavinos@uni-wh.de 
allotted to each subdivided among distinct and separate departments. Hence a double security arises to the rights of the people. The different governments will control each other, at the same time that each will be controlled by itself" (The Federalist Papers 1961, No. 51, Madison, p. 323).

Federalism as a constitutional structure provides a system of "checks and balances" which in the long-run promotes the liberty of individuals of the respective polity. Federalism is a constitutionally anchored constraint to political power and to the possibility of curtailing individual liberty. Hence, a main argument for federalism is that it secures individual liberty.

Though the vital importance of federalism for securing individual liberty is broadly acknowledged, ${ }^{1}$ the exact relationship between the two has been insufficiently analyzed. The theories of dual, cooperative, and competitive federalism, though quite fully developed, have not provided any coherent view of the mechanism for how federalism influences individual liberty. It is mainly other aspects that are regularly discussed (e.g., Karmis and Norman 2005), like the relationship between federalism and multiculturalism, democracy or fiscal policies; but there is literally no work highlighting the mechanism of how a federalist system affects individual liberty. ${ }^{2}$

In this paper, I shall provide a description of the mechanism that links federalism and individual liberty, paying due attention to the most important effects of a federalist structure on the liberty of the citizens. Much of the literature on the issue is of a normative flavor, trying to answer the question how the political system ought to react so that individual preferences can be best satisfied. I am going to proceed in a positive way. My problem is how a federal system will, under certain plausible assumptions, affect the liberty of the individual; in other words, I want to investigate what will be the reaction of the constituency to a federalist political system and how this reaction will influence the individual liberty. Liberal thinkers (in the original, European sense of the term) are concerned with the problem of responsiveness; my concern in this article is to show the complex influence on the individual liberty that emerges by allowing multiple governments to offer diverse institutional arrangements to citizens.

\section{Arguments that link federalism to individual liberty}

There is a series of arguments that link federalism to individual liberty, some of them already contained in the Federalist Papers and some of them suggested in contemporary discussions. The core issue is what Riker (1964) has called the fundamental dilemma of federalism, i.e., how to have a central government that is strong enough to provide a check on the lower level governments, but is not so strong that it overwhelms the states. The first way that lower level governments can

\footnotetext{
${ }^{1}$ See the remark of Elazar (1987, p. 91): "The central interest of true federalism in all its species is liberty".

${ }^{2}$ See the remark of Chemerinsky (2001, p. 929): "The point is that none of the traditional justifications for federalism explain why it is likely to enhance liberty nor is it ever explained why federalism is needed to secure liberty".
} 
check the central government is laid out in Federalist Nr. 24, 25, and 46: the greater loyalty that citizens would tend to feel to their states than to the federal center would tend to check any move to despotism by the center, in extreme cases even through armed resistance. A second way was already proposed by de Montesquieu (1748/ 1989, p. 132): "If a sedition occurs in one of the members of the confederation, the others can pacify it. If some abuses are introduced somewhere, they are corrected by the healthy parts". According to this argument it is the other lower level governments that can check any move towards abuse by a lower level government, without the central government engaging in any correction. The third way is described by the so-called republican guarantee clause of the US Constitution (Article IV, Sect. 4): “The United States shall guarantee to every State in this Union a Republican Form of Government, and shall protect each of them against Invasion; and on Application of the Legislature, or of the Executive (when the Legislature cannot be convened) against domestic Violence". In other words liberty is protected by means of a federal check on the lower level governments.

Levy (2007, p. 309), presenting the three arguments above, speaks of "mechanisms by which the founding generation imagined that federalism might enhance liberty". However, though these arguments are important and probably valid, it is a real stretch to speak of mechanisms in this context. The notion of mechanism is at the center stage of the discussions of casuality and explanation in the philosophy of science, and it is increasingly acknowledged that a scientific explanation of a phenomenon can only be provided if a causal mechanism is specified (Machamer et al. 2000, P. Machamer, 2008, unpublished manuscript, Knight 2009). The links between federalism and liberty sketched above are nothing more than the first argumentative steps towards the construction of a more comprehensive mechanism illuminating the relationship yet to be developed.

The same is true for the contemporary discussions of federalism. The most frequently repeated argument in favor of federalism is that states or local governments are closer to the people and thus more likely to be responsive to their needs. Vaubel (1995) offers, for example, two justifications for a federalist structure: (1) that regional preferences differ; and (2) that competition among governments protects the freedom of the individual. His argument is representative for the standard perspective that the greater responsiveness to regional preferences is ipso facto a guarantee for liberty. Shapiro (1995) also suggests that in principle the smaller the area governed, the more responsive the government will be to the preferences of the constituency, and thus the better it will be able to protect individual liberty. ${ }^{3}$ However, as Chemerinsky (2001, p. 927) sharply observes: "[T]his premise is highly questionable; it assumes that popular sentiment is likely to be rights progressive rather than rights regressive. To the extent that voters at the state and local level prefer rights regressive legislation-or more likely a rule that abuses a particular minority group_-greater responsiveness increases the dangers of government tyranny. In other words, the substantive result of decreasing tyranny

\footnotetext{
3 See Shapiro (1995, p. 91f.): "[O]ne of the stronger arguments for a decentralized political structure is that, to the extent that the electorate is small, and elected representatives are thus more immediately accountable to individuals and their concerns, government is brought closer to the people, and democratic ideals are more fully realized".
} 
will not always be best achieved by the process approach of maximizing electoral responsiveness; indeed, the reverse might well be the result".

Buchanan (1995, p. 259), for his part, suggests "that a coherent classical liberal must be generally supportive of federal political structures, because any division of authority must, necessarily, tend to limit the potential range of political coercion". In his theory of competitive federalism, he elaborates on the prospects for exit as constraints on political control over the individual and introduces, thus, a very important analytical category - the exit option - in the analysis of the relationship between federalism and individual liberty. ${ }^{4}$ The theory known as "market preserving federalism" (Weingast 1995; Qian and Weingast 1997) suggests ways that a federalist system can be designed in this way in order to effectively preserve markets and provide incentives for long-run economic development (Mantzavinos 2001). Other theoretical developments in this tradition analyze the ways that the institutions of federalism can be sustained, stressing that the chances of survival of a federalist system crucially depend on federal structures being self-enforcing, i.e., they depend on the center and the states having incentives to fulfill their obligations within the limits of federal bargains (de Figueiredo and Weingast 2005). While these contributions are very valuable indeed, they do not provide any insights into the working properties of a mechanism that links federalism and individual liberty. I will undertake such an attempt in what follows.

\section{Federalism and direct individual liberty}

Federalism as a constitutional principle can only be effective if enough power is ceded to a number of regulative authorities, which can use it in order to offer different institutional arrangements. Whether these be states or local authorities, the main idea of federalism consists of numerous jurisdictions making decisions on public issues and providing diverse institutional rules to the citizens of the respective jurisdictions. Thus, federalism permits jurisdictions to offer alternative packages of public goods and of legal rules for the organization of different aspects of the public and private life of the constituency.

Characteristic of federal polities is their noncentralized structure. The powers of government are diffused among many centers rather than being concentrated in a single center. Noncentralization is different from decentralization. In a decentralized system there exists a central authority that can decentralize or recentralize according to its desires, whereas "in a noncentralized political system, power is so diffused that it cannot be legitimately centralized or concentrated without breaking the structure and spirit of the constitution" (Elazar 1987, p. 34f).

This noncentralization implies a plurality of jurisdictions within a political system. For federalism, the existence of plurality of authorities is decisive. Normally in the literature, as well as in accord with common sense, a federal

\footnotetext{
4 "Exit" has been sufficiently used, of course, in the theory of competitive federalism originating in the classic Tiebout (1956) article and more generally in the economics of federalism (for a collection see Ribstein and Kobayashi 2007). However, this literature pays no attention to the question how the possibility of exiting a jurisdiction affects individual liberty.
} 
political system is associated with a plurality of authorities. This plurality of jurisdictions can lead alternatively, dependent on different factors, either to a homogeneous or a diverse political landscape. The existence of plural authorities might result in offering either homogeneous or diverse institutional rules to a constituency. Although it is possible that the existence of a plurality of authorities may lead to entirely homogeneous institutional rules, empirically it does not seem to be the rule. ${ }^{5}$ What occurs more often is that a plurality of jurisdictions legislating in a complex social world will provide diverse institutional rules. The most interesting case empirically is, thus, that plurality will lead to diversity. Hence, I shall abstract from the first case and I shall assume that empirically the essential characteristic of a political system based on a federalist structure is that diverse institutional rules are made available by numerous jurisdictions. Therefore, when I speak of federalism in this paper, I shall mainly mean that local governments offer various "package deals" or mixes of services or institutional arrangements to their constituents. This diversity per se has always been seen as protective of the individual liberty of the citizens $^{6}$ : What is interesting in our context is how this diversity is perceived by any single individual in a polity, i.e., the effects of federalism for any individual citizen of a polity.

This effect obviously has something to do with the individual freedom of choice. If alternative institutional arrangements are offered to an individual, then he has the possibility of choosing the one that he finds best, i.e., the one that satisfies more completely his desires. The diversity of institutional arrangements per se enhances the alternatives open to the individual citizen. His degree of freedom is augmented, because in a federal system he can choose to live in the jurisdiction that offers him the best set of institutional rules. This is the positive formulation of the effect of federalism on individual liberty: diversity broadens the possible set of choices of jurisdictions for every citizen. But one may also formulate the issue in a negative way. Using the familiar distinction between "exit" and "voice" (Hirschman 1970), every individual can change the jurisdiction under which he lives, if he is dissatisfied with the one he currently lives under. In other words, he can exit the jurisdiction that does not provide the set of institutional arrangements that he approves of. Stated in these terms, diversity of jurisdictions and institutional arrangements guarantees the existence of exit options for any dissatisfied citizen, and thus enhances his individual liberty.

Every member of an organization normally possesses two options with which he can show his dissatisfaction: "exit" and "voice". The effect of these two different

\footnotetext{
${ }^{5}$ An anonymous referee has pointed out that decentralization does not encourage very much institutional diversity. He referred to the cases of the US, Canada, and Australia which are regarded to be three of the four most decentralized federal systems, but their state governments have relatively little diversity. I have no space here to discuss the empirical literature on decentralization and heterogeneity (see Mueller 2003, Chap. 10.5 for a competent review), and I would only like to make two remarks. First, decentralization must be distinguished from noncentralization. Second, since I am primarily interested in developing a theoretical argument, I, of course, do not claim its validity for all cases, but only for those for which it is empirically applicable.

${ }^{6}$ Already Madison noted: "In order to lay a due foundation for that separate and distinct exercise of the different powers of government, which to a certain extend is admitted on all hands to be essential to the preservation of liberty[...]" (The Federalist Papers 1961, No. 51, Madison, p. 321).
} 
decisions of individual members of organizations is to serve as recuperation mechanisms for organizational slack by showing the discontent with realized policies. But although "voice" can be effective in increasing responsiveness to the wishes of the members of organizations, it is the exit-option which is most powerful in signalling to the management of an organization or the government of a polity that members or citizens are dissatisfied with it. ${ }^{7}$ In my discussion of the relationship between federalism and individual liberty, it is "exit" that constitutes an increase in liberty rather than "voice". And the possibility of "exit" is given only in a federal political system with diverse jurisdictions.

I want to call this relationship between diversity of jurisdictions and the freedom of the individual to choose among jurisdictions the direct effect of federalism on individual liberty. Accordingly, I want to call this kind of liberty direct individual liberty (DIL). The respective function of DIL can be written as:

$$
\mathrm{DIL}=\mathrm{f}(\text { Div }), \frac{\mathrm{dDIL}}{\mathrm{dDiv}}>0
$$

where DIL is direct individual liberty, Div is diversity of jurisdictions available for individuals to choose. It is important that the first derivative of the function is greater than zero, meaning that, as the diversity of jurisdictions increases, the DIL also increases.

This simple function is represented geometrically in Fig. 1. On the ordinate the DIL is presented; and on the abscissa the diversity of jurisdictions is shown. The curve of DIL will slope upward throughout all of its range, showing the direct effect of federalism on individual liberty. The more jurisdictions offer different institutional settings, the greater the range of options for any individual, and thus the greater the possibility for an individual to choose among them. The zero point of this function will show the case of a citizen living within one jurisdiction and having no option to leave it. ${ }^{8}$

\section{Diversity of jurisdictions and exit costs}

So far we have discussed the impact of the diversity of jurisdictions on the freedom of the individual to choose where he wants to live. Obviously, a crucial factor in the above analysis is the assumed mobility of the individuals. In order for a citizen to be able to realize the benefits of the existence of numerous jurisdictions offering diverse institutional arrangements, he must also avail himself of the respective mobility to move from one jurisdiction to another. This mobility of the individual is

\footnotetext{
${ }^{7}$ Hirschman (1970, p. 83) stresses the fact that although prima facie exit and voice are alternative mechanisms, their relationship is more complex. "Now it appears that the effectiveness of the voice mechanism is strengthened by the possibility of exit. The willingness to develop and use the voice mechanism is reduced by exit, but the ability to use it with effect is increased by it".

8 At this point it should be mentioned that no assumptions are made about the second derivative of the function, i.e., how the curve looks exactly. I have used a linear interpretation only because of its simplicity. The important fact in this and the other figures is only that the relationship is a positive or a negative one.
} 


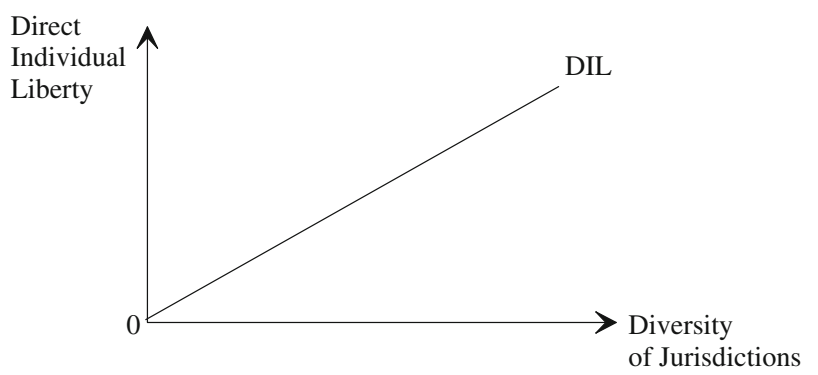

Fig. 1 Relationship between diversity of jurisdictions and direct individual liberty

enhanced whenever the exit costs are low, i.e., whenever he can move across jurisdictions without having to bear high personal costs. And in an opposite manner, his mobility is diminished whenever the exit costs that he has to bear in the case of making the exit-decision are high.

Hence in this context, it becomes important to provide a relationship between the diversity of jurisdictions, i.e., federalism, and the exit costs that the citizen must bear. (In the next section I will analyze how these exit costs are linked to individual liberty.) How does the plurality of authorities exerting discretionary political power affect the decision of a citizen to exit from the jurisdiction under which he lives?

In stating the link between diversity of jurisdictions and DIL, we have not defined precisely what we mean when saying jurisdictions are diverse. Since the interesting issue is only the existence of diverse political authorities offering different policy packages and increasing per se the freedom of choice for individuals, the exact meaning of such diversity of jurisdictions has not been developed. I want now to define the diversity of jurisdictions as it appears to an individual as the difference between the new behavioral routines that he has to get accustomed to in the new jurisdictions minus the behavioral routines of the individual within his initial jurisdiction.

For my purposes, this definition covers sufficiently the diversity of political authorities, i.e., how the plurality of jurisdictions affects the individual life of the citizens. When an individual lives within one jurisdiction, his behavior is channelled by the respective institutional setting. The jurisdiction, by providing rules ranging from healthcare, welfare, and education to transport, air pollution, and town planning, affects directly and indirectly the private life of any citizen. If an individual moves to a new jurisdiction that provides different sets of rules, it is obvious that the individual must first get accustomed to it, before he can lead a happy life. For every citizen, the diversity of jurisdictions takes the form of different behaviors that an individual must adopt if he decides to exit from one jurisdiction and live in a new one.

For his exit-decision, two sets of factors are important for an individual: (1) the informal rules, i.e., of culture, morals, language, etc.; and, (2) the diversity of formal rules. Obviously, it is very difficult for an individual to leave the jurisdiction in which he lives and move to another one if, for example, another language is spoken in the new one. Cultural diversity increases the exit costs of any individual and very often impedes mobility. As David Hume stated it: "Can we seriously say, that a poor 
peasant or artisan has a free choice to leave his country, when he knows no foreign language or manners, and lives from day to day, by the small wages which he acquires? We may as well assert, that a man, by remaining in a vessel, freely consents to the dominion of the master; though he was carried on board while asleep, and must leap into the ocean, and perish, the moment he leaves her" (Hume 1907, p. 451).

Although it is very interesting to explore the influence of cultural diversity on exit costs of individuals, if one wants to explain the impact of federalism as a constitutional structure on liberty, then only the diversity of formal rules is relevant. The influence of culture on the exit-decision of the individual would blur our analytical argument for the moment; it is the impact of formal rules, i.e., legislations, decrees, etc. on exit costs that we are concerned with, because a federal system consists of the diversity of such formal rules. And since cultural diversity is not a constitutive element of a federalist principle, its influence will be regarded in the next analytical step (Sect. 8).

Concentrating thus on the impact that the diversity of formal rules has on the individual decision of exiting, the following causal relationship seems obvious: the greater the diversity of formal rules offered by state or local authorities, the greater the change of behavioral routines needed for the individual in case of exiting from his initial jurisdiction, i.e., the higher are the exit costs that he has to bear. But why and in what form do different formal rules effect a change of behavior for which adaptation costs are to be born?

As we have stated before, institutions can affect individual behavior in an indirect, but quite powerful, way. When a state or local authority with political power enacts legislation, at the same time it provides the framework within which citizens of the respective jurisdiction can act. Formal rules are the primary restriction in the individual calculus of choice, because normally a consequence of breaking of these is more or less severe punishment in monetary or non-monetary terms. In other words, legal rules directly affect the options open to an individual and thus indirectly affect his choices and corresponding behavior. The impact of public life on individuals is always one created through rules enacted by the political authority and one that constrains the choice options of the individuals.

What is of importance to us now is to introduce the temporal perspective into the analysis. Since even the most mobile citizens do not change jurisdictions very often, but only a limited number of times throughout their lives, it is not only the impact of formal rules on choice that is to be elucidated, but also the impact on the long-run behavior of individuals. This issue is stated sufficiently by Vanberg and Kerber (1994, p. 205): "When residents are dissatisfied with 'their' government, they can escape that government only by moving into a different jurisdiction, a transaction that is in general significantly more costly than changing sellers in market exchange. There are potentially considerable exit costs involved, in particular in the form of 'sunk capital' that has to be given up or is devalued significantly by the change in residential location. This includes as a major component accumulated knowledge, skills and expertise that are adopted to the particular environment, but have comparatively little value in alternative environments".

Institutions, understood as the rules of the game, channel the long-run behavior of citizens (Mantzavinos et al. 2004). Formal rules define the restrictions for individual 
behavior and in this way lead the inclinations and skills of individuals into a certain direction. This means that to a great degree people form their habits according to the institutional framework within which they live. But habits, in turn, possess selfperpetuating dynamics. As Marshall put it: "[...] the more good music a man hears, the stronger is his taste for it likely to become" (Marshall 1920, p. 79). What lies behind this statement is that the more a person is accustomed to act in a certain way, the higher is the probability that he will experience a greater pleasure when acting in the same way in the future.

Obviously it is not the process of habit formation that concerns us here, but the fact that once one has acquired a habit, one will get utility by practicing it. Rawls speaks in a similar way of a general psychological law which he calls the "Aristotelian Principle": "other things equal, human beings enjoy the exercise of their realized capacities (their innate or trained abilities), and this enjoyment increases the more the capacity is realized, or the greater its complexity. The intuitive idea here is that the human beings take more pleasure in doing something as they become more proficient at it, and of two activities they do equally well, they prefer the one calling on a larger repertoire of more intricate and subtle discriminations" (Rawls 1971, p. 426). ${ }^{9}$ The economists Stigler and Becker stated the same law in a somewhat more technical manner (Stigler and Becker 1977). The main idea is that something like a "consumption capital" exists which is formed during the period in which one is involved in acting in a specific way (in Marshall's example, this would be listening to good music). Once acquired, this human "consumption capital" has as an effect that every time one is exercising one's habit, one must devote less energy to it in comparison to one's other activities. This means that the "shadow price" of, for example, listening to music is lower than spending one's time on other activities. This cheapness of exercising one's habit due to accumulated skill and experience provides an incentive for the individual and finally leads him to exercise it more frequently in the future, an insight that is supported by current psychological research (Anderson 2005, Chap. 9, Mantzavinos 2005, p. 121ff).

After the formulation of this psychological law, whether in terms of psychology, as an Aristotelian Principle, or in terms of economics, the relevant link for us must be obvious: if formal rules serve as restrictions to individual behavior, and if once habits are formed so as to tend to perpetuate themselves, then formal (legal) rules affect the long-run individual behavior by channelling it in certain ways. This means then that the individual, whenever he possesses the choice to live under different formal rules, i.e., jurisdictions, must always reckon with a consequent compulsory change of his habits and behavioral routines. This, in turn, is equivalent to psychological costs, which every individual who moves from one jurisdiction to another must bear. ${ }^{10}$ If

\footnotetext{
${ }^{9}$ What is important in this context is "that enjoyment and pleasure are not always by any means the result of returning to a healthy or normal state, or of making up deficiencies; rather many kinds of pleasure and enjoyment arise when we exercise our faculties" (Rawls 1971, p. 426).

10 "Regardless of the level of government, exit entails cost, not only economically but, perhaps even more importantly, psychologically. Normally, an individual feels an attachment to or part of the community in which he is born and raised. It is where his friends are. He identifies with it. It is 'his' community. He is a member of it and feels loyalty to it. It is where his 'roots' are. It is 'home'. Thus, exit, like revolution, will not occur 'upon every little mismanagement of public affairs' or disagreement over public policy”. (Osterfeld 1989, p. 171).
} 


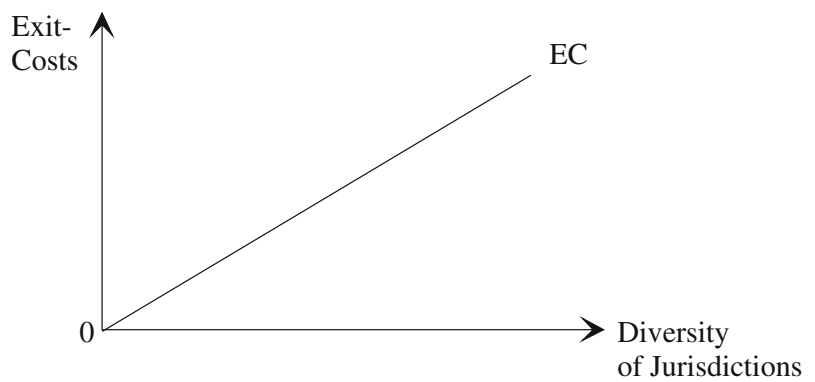

Fig. 2 Relationship between diversity of jurisdictions and exit-costs

one labels these costs as "exit costs", then a positive casual relationship exists between diversity of formal rules, i.e., jurisdictions, and exit costs for the mobile individual.

We may write the exit costs function as:

$$
\mathrm{EC}=\mathrm{g}(\text { Div }), \text { with } \frac{\mathrm{dEC}}{\mathrm{dDiv}}>0
$$

where EC is exit costs of individual, Div is diversity of jurisdictions available for the individual to choose. The first derivative of the exit costs function is positive, meaning that as the diversity of jurisdictions increases, the exit costs for the individual also increase.

The exit cost function is represented geometrically in Fig. 2. On the ordinate the exit costs of the individual are represented; on the abscissa the diversity of jurisdictions is shown. The curve of exit costs will slope upward throughout all of its range, showing the positive effect of federalism on the exit costs of the individual. The more the jurisdictions offering different institutional settings, the greater the pains for an individual to adapt himself to the new institutional environment if he decides to exit and thus, the higher the indivdiual's exit costs are. The zero-point illustrates the case of no practical diversity among jurisdictions, i.e., the case of a centralized political system; in this case naturally the exit costs are zero because there is no exit-opportunity.

\section{Exit costs and indirect individual liberty}

So far we have stated the casual relationship between the diversity of jurisdictions and the exit costs of the individual. The greater the diversity, the higher the exit costs for an individual who decides to change jurisdiction. But since we are primarily interested in the effects of federalism on the freedom of the individual, the problem of the relationship between exit costs and individual liberty arises.

Obviously, this relationship is a negative one. The higher the exit costs for any citizen, the more difficult the decision to change jurisdiction and thus, in effect, the less his individual liberty becomes. The psychological costs of adaptation to a new institutional environment function as an impediment to the individual freedom to 


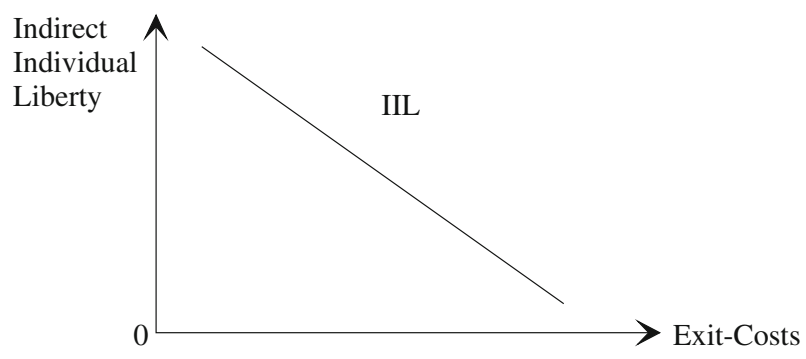

Fig. 3 Relationship between exit-costs and indirect individual liberty

choose the jurisdiction under which he wants to live. This is the indirect effect of diversity of jurisdictions imposed through higher exit costs on the individual liberty. Accordingly, I want to call this kind of liberty indirect individual liberty (IIL). The respective function of IIL can be written as:

$$
\mathrm{IIL}=\mathrm{h}(\mathrm{EC}), \text { with } \frac{\mathrm{dIIL}}{\mathrm{dEC}}<0
$$

where IIL is indirect individual liberty, EC is exit costs of the individual. The first derivative of the IIL function is negative, meaning that as the exit costs of the individual increases, his IIL decreases.

The IIL function is presented geometrically in Fig. 3. On the ordinate the IIL is presented; on the abscissa the exit costs are shown. The curve of IIL will slope downwards throughout all of its range, showing the negative effect of exit costs on IIL.

\section{Diversity of jurisdictions and indirect individual liberty}

In the preceding section we have stated the negative relationship between exit costs and IIL. This casual relationship holds, irrespective of what it is that causes exit costs. As we have mentioned in Sect. 4, high exit costs can obviously be caused by cultural diversity between jurisdictions, such as different languages, different standards of behavior, etc. But as we are concerned here with the impact of federalism as a constitutional system on the individual liberty, what matters is how exit costs caused by the application of a federalist political system affect individual liberty. In other words, what is important is the impact of the diversity of jurisdictions on exit costs, and through those costs, on the IIL.

It should be obvious that this causal link between federalism, i.e., diversity of jurisdictions, and IIL is a negative one. We have seen that a consequence of the diversity of jurisdictions available for the individual to choose from is that his or her exit costs increase. And a consequence of every increase in the exit costs is a decrease in the IIL. Thus an overall consequence of the diversity of jurisdictions is a decrease of IIL. 


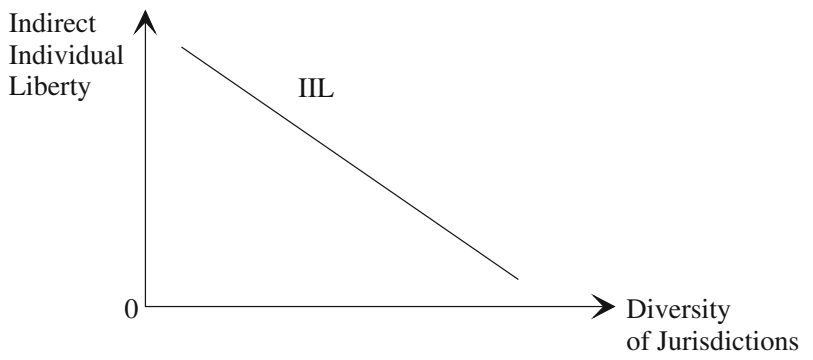

Fig. 4 Relationship between diversity of jurisdictions and indirect individual liberty

If we take a look at our functions, the above means that since diversity of jurisdictions causes exit costs and exit costs are linked to IIL, we have the case of a composition of two functions

$$
\mathrm{IIL}=\mathrm{h}(\mathrm{EC}) \text { and } \mathrm{EC}=\mathrm{g}(\text { Div }) .
$$

The relationship can be written as:

$$
\mathrm{IIL}=\mathrm{h}[\mathrm{g}(\text { Div })]
$$

Since the first derivative of IIL is negative, i.e., $\frac{\mathrm{dIIL}}{\mathrm{dEC}}<0$ and the first derivative of EC is positive, i.e., $\frac{\mathrm{dEC}}{\mathrm{dDiv}}>0$ the derivative of the function $\mathrm{IIL}=\mathrm{h}[\mathrm{g}$ (Div)] must be negative, since:

$$
\frac{\mathrm{dIIL}}{\mathrm{dDiv}}=\frac{\mathrm{dIIL}}{\mathrm{dEC}} \frac{\mathrm{dEC}}{\mathrm{dDiv}} \text { and with } \frac{\mathrm{dILL}}{\mathrm{dEC}}<0 \text { and } \frac{\mathrm{dEC}}{\mathrm{dDiv}}>0
$$

it follows that $\frac{\mathrm{dIIL}}{\mathrm{dDiv}}<0$.

In other words, the slope of the function of IIL in relation to the diversity of jurisdictions is negative. This relationship is presented geometrically in Fig. 4. This figure merely presents Figs. 2 and 3 together in one, so that the intermediate link of the exit costs is omitted. On the ordinate the IIL is represented; on the abscissa the diversity of jurisdictions is shown. The IIL curve will slope downward throughout its whole range, showing the negative effect of the diversity of jurisdictions (through exit costs) on the IIL.

\section{Federalism, direct and indirect individual liberty}

So far in our exploration of the complex relationship between federalism and individual liberty, we have put forward two lines of argument, a direct and an indirect one. The direct argument states the positive impact of federalism, i.e., diversity of jurisdictions, per se on individual liberty. Since diversity broadens the possible set of choice among jurisdictions for the citizen, there is a direct effect of federalism on his individual liberty. This is more or less, explicitly or implicitly, the 
main argument for federalism stated in the literature by the advocates of a noncentralized political system.

Although this line of reasoning is definitely right, it is nevertheless incomplete. A full treatment of the problem of the impact of federalism on individual liberty must also contain the indirect effect of federalism on individual liberty. This indirect line of argument concerns the effect institutional diversity has of increasing the degree of difficulty a citizen has to move from one jurisdiction to another. A consequence of this fact, which is an unintended result of a federalist organization of a polity, is a decrease in individual liberty. This effect, which is an indirect one because it is neither designed nor planned by the constitutional designers, causes a diminution of what I have called the IIL. It is, in a certain way, a quasi-automatic effect, caused and enhanced by the peculiarity of the human nature to adapt well to prevailing institutional settings and thus to find it difficult to re-adapt to new ones.

How, then, are these two effects of federalism, the direct and the indirect one, to be best handled theoretically? To answer this question, the geometrical figures worked out in the paper will be an aid. In Fig. 1 we have shown the direct effect of federalism, i.e., of the diversity of jurisdictions, on individual liberty. In Fig. 4 we have shown (by summing up Figs. 2, 3) the indirect relationship of federalism on individual liberty. If we now put together Figs. 1 and 4 in one diagram, we then will have the total effect of federalism on individual liberty.

In Fig. 5 the curves of both DIL and IIL are depicted-namely, at the point Op on the abscissa, where the two points intersect the optimum degree of diversity of jurisdictions is presented. At this point the positive and negative effects of federalism on individual liberty are counterbalanced. Since the geometrical representation of the problem is only appropriate for the purpose of illustration, it is obvious that there is not only one optimum degree of diversity, but rather a wide range of optima-all the points between $\mathrm{A}$ and $\mathrm{B}$ on the graph.

At point A, for example, the case of a more limited federalist political system is presented. The direct effect on individual liberty is thus rather small, whereas, since only a small amount of diversity of institutional arrangements is offered to the citizens, the exit costs are low and thus the indirect effect on individual liberty is quite great. In the case of a more radicalized federalism (point B), the inverse phenomena appear. The direct effect is great, while exit costs are high and the

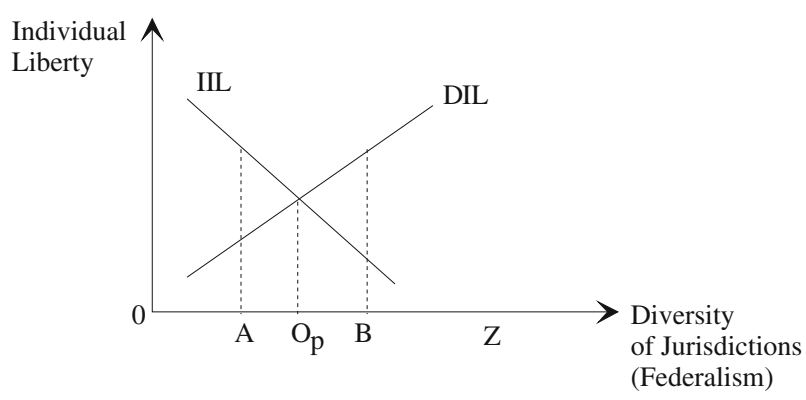

Fig. 5 Relationship between diversity of jurisdictions and individual liberty 
indirect effect is small. Hence, from a normative point of view, if a constitutional federalist design is to be implemented, the federalism most conducive to individual liberty is a moderate one.

$\mathrm{OA}$ and $\mathrm{BZ}$ represent the federalist structures which, from the viewpoint of their effect on individual liberty, are less appropriate. I want to call them the cases of ineffective federalism. They show the cases of centralized federalism and radical federalism. They are both nonoptimal because either the direct or the indirect effect dominates and thus federalism misses its primary aim-to secure and enhance individual liberty. This becomes obvious when one examines the two extreme cases: a centralist political system without federalism, and a radical federalist political system. In the first case, the fact that citizens have to bear zero exit costs is obviously of no consequence. Why should it matter that the citizen enjoys great IIL when this is thoroughly ineffective since he does not have the possibility of choosing among jurisdictions? And in the other extreme case, that of radical federalism, it is likewise inconsequential that citizens have the possibility of choosing among every thinkable jurisdiction. Why should it matter that the citizen enjoys great DIL when this is thoroughly ineffective since de facto (because of the peculiarity of human nature discussed above) he is not capable of using it? Therefore, these two extremes present cases of ineffective federalism. ${ }^{11}$

\section{Mobility, federalism and individual liberty}

So far we have explored the impact of the diversity of jurisdictions on individual liberty. By stating the two effects, the direct and the indirect one, we have not explicitly considered how individual mobility would affect the analysis. In other words, we have not investigated how differences in mobility and/or adaptability between individuals influence the working of federalism. In Sect. 3 we stressed the fact that in order to analyze the impact of federalism on individual liberty only the diversity of formal rules were important. After having reached our theoretical results, we can, in a further analytical step, explore the adaptability of individuals as a further determinant of individual liberty. The question in this section is thus: under conditions of different mobility of citizens, how is the optimum degree of federalism modified in respect to its impact on individual liberty?

The comparison between United States and Europe is interesting in this respect. In the United States the citizens are very mobile in different respects and change jurisdictions quite frequently. ${ }^{12}$ Obviously, if we compare the case of the United

\footnotetext{
11 The results of my analysis are hence different to those of Osterfeld (1989). He advocates radical federalism as a means of enhancing responsiveness of government without taking into consideration the indirect effect; he thus reduces the complexity of the problem. Only if both effects, the direct and indirect, are seen, can we reach a complete treatment of the problem of the appropriate extent of federalism.

12 Dye (1990, p. 16) refers to the fact that between 1980 and 1985, 40\% of Americans changed their residence, and nearly 10 percent moved to a different state. And Walzer stresses the fact that in the United States the individuals are continually in motion. He speaks of the four mobilities: (1) geographic, (2) social, (3) marital, and (4) political. In respect to political mobility Walzer remarks: "Loyalty to leaders, movements, parties, clubs and urban machines seems to decline rapidly as place and social standing and family membership become less central in the shaping of personal identity. Liberal citizens stand outside
} 


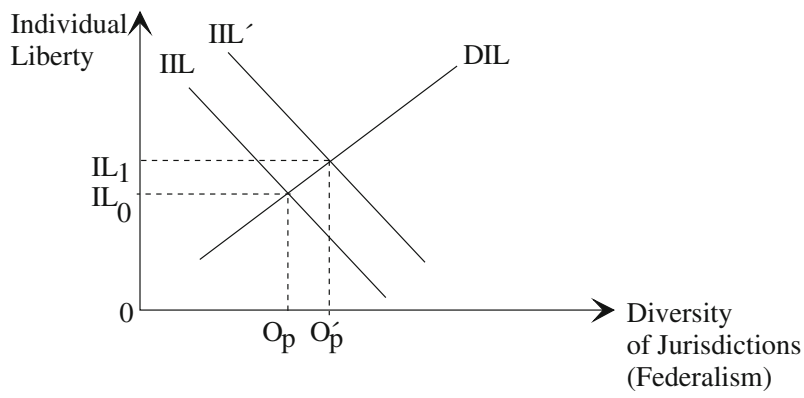

Fig. 6 The effect of cultural homogenecity (or mobility) on individual liberty

States with that of a prospective European Union organized as one polity, the mobility of the citizens in the latter is much lower. In our example, regarding only language, it is much easier for an American to move from one state to another than for a European. Cultural differences, in this case language, increase the exit costs of Europeans, making it more difficult to move to a new jurisdiction. An English citizen can move more easily to the USA than a French citizen; and an Austrian can move more easily to Germany than a Portuguese. The crucial factor is obviously cultural homogeneity: the effects of a federalist structure in a culturally homogeneous polity will be different from those in a polity with cultural differences between the local jurisdictions.

This result can be stated as following: in a culturally homogeneous polity, federalism will work better to secure individual liberty than in a culturally heterogeneous polity. This will be so because cultural homogeneity implies the enhanced mobility of citizens; and greater mobility means lower exit costs for any given federalist structure. Thus the indirect effect on liberty will be greater when the mobility or adaptability of the citizens is greater.

Let us see how the analysis can be presented in a graph where the enhanced mobility or adaptability of the citizens is assumed. In Fig. 6 the curve of IIL is shifted to the right (IIL'). This is so because, for a given diversity of jurisdictions, their exit costs are lower due to greater mobility of the citizens. In other words, because-for some external reasons (i.e., cultural homogeneity) - the citizen is more mobile, he or she is more prone to make the exit-decision, regardless of the degree of federalism in the political system. Since the individual's exit costs are thus lower, and according to the function IIL $=h(E C)$, the IIL will be greater. Geometrically this is equivalent to a shift of the IIL-curve to the right.

The new optimum point-in this case, of cultural homogeneity of the polity or of greater per se mobility of the citizens (which is the same)-is $\mathrm{Op}^{\prime}$, which is to the right of the old optimum point Op. This means that federalism in a mobile society

Footnote 12 continued

all political organizations and then choose the one that best serves their ideals or interests. They are, ideally, independent voters, that is, people who move around; they choose for themselves rather than voting as their parents did, and they choose freshly each time rather than repeating themselves" (Walzer 1990, p. 12). 
may be more radical, i.e., the sets of institutional arrangements might vary more. The application of the same degree of federalism in a case where the mobility of citizens is greater can lead to an enhancement of individual liberty compared to the case in which there is low mobility (IL1 compared to IL0). In our example this would mean that the same federalist political system when applied in the United States and in Europe would lead to a greater increase in individual liberty in the United States than in Europe.

But why is this so? Apparently because the European citizens perceive the diversity of jurisdictions and institutional arrangements as an impediment rather than as a chance to better their lives. A direct result of the analysis for Europe would then be that the more the cultural integration of the different European people proceeds, the more beneficial will be the effects of a federalist system on the individual liberty.

\section{Some limitations}

The analysis has a series of limitations. The most serious one is due to the way liberty is conceptualized and the subsequent use of equations and diagrams, as if liberty were a well-defined variable amenable to such an analysis. The standard analysis of federalism uses the formal machinery of the public choice theory; it is largely based on the use of the concept of utility, which makes the respective models largely testable. Since my analysis focuses on liberty rather than utility, it is not possible to draw on the large literature in the economics of federalism and political science that formally analyzes the working properties of federalist systems. However, admitting the somehow messy character of transforming the concept of liberty to an analytical variable, I do think that the simplicity of the equations and diagrams do provide an effective way of highlighting the literary arguments in the text and of illuminating the mechanism that links federalism and individual liberty.

Another serious limitation of the analysis concerns the empirical value of the theoretical insights offered in this paper. Other than a sketchy comparison between the USA and the European Union with respect to the mobility of citizens, I have not provided empirical considerations of any sort here, the focus of analysis being exclusively of a theoretical nature.

Lastly, since exit costs mainly result from habitual behavior and routines generated by particular political institutions, the analysis is mostly valid in the long run. In other words, the time horizon for which the analysis is applicable cannot be the short run, since exit costs depend on the adaptation of the behavioral routines of the citizens, which need considerable time to take place. Besides, exit cost effects of institutional diversity will obviously vary with age and income, a dimension that is not captured by the analysis.

\section{Conclusion}

My concluding remarks can be brief. I have shown that federalism has an ambivalent overall effect on individual liberty. I have indicated two effects, one 
direct and one indirect. A complete treatment of the relationship between federalism and individual liberty should consider both effects. The optimum range of diversity of jurisdictions, i.e., of federalism, has been shown to lie where the two effects counterbalance each other. Increased mobility or adaptability of citizens can lead to a more effective realization of individual liberty.

It is obvious that this analysis holds irrespective of which form of federalismdual, cooperative or competitive-is assumed. As long as federalism is understood as the constitutional principle of noncentralization of power, the analysis likewise holds. A further insight concerns the application of federalist structures on polities with different degrees of cultural homogeneity and thus citizen-mobility. These results should have profound consequences for the ongoing debate on the prospective of the European Union.

\section{References}

Anderson, J. R. (2005). Cognitive psychology and its implications (6th ed.). New York: Worth Publishers. Buchanan, J. M. (1995). Federalism and individual sovereignty. Cato Journal, 15, 259-268.

Chemerinksy, E. (2001). Does federalism advance liberty? Wayne State Law Review, 47, 911-930.

De Figueiredo, R., \& Weingast, B. (2005). Self-enforcing federalism. Journal of Law, Economics, and Organization, 21, 103-135.

de Montesquieu, C. (1748/1989). The spirit of the laws. Cambridge: Cambridge University Press.

Dye, T. R. (1990). American federalism. Competition among governments. Massachusetts/Toronto: Lexington Books.

Elazar, D. J. (1987). Exploring federalism. Tuscaloosa: University Alabama Press.

Hamilton, A., Madison, J., \& Jay, J. (1961). In The Federalist Papers. New York: Signet Classics. Hirschman, A. O. (1970). Exit, voice, and loyalty. Cambridge and London: Harvard University Press. Hume, D. (1907). Essays, moral, political and philosophical. Vol. 1, London: Longmans Green and Co. Karmis, D., \& Norman, W. (Eds.). (2005). Theories of federalism: A reader. London: Palgrave Mcmillan. Knight, J. (2009). Causal mechanisms and generalizations. In Mantzavinos (Ed.) (2009).

Levy, J. T. (2007). Federalism and the old and new liberalisms. Social Philosophy \& Policy, 24, 306-326. Machamer, P., Lindley, D., \& Carl, C. (2000). Thinking about mechanisms. Philosophy of Science, 67, $1-25$.

Mantzavinos, C. (2001). Individuals, institutions, and markets. Cambridge: Cambridge University Press. Mantzavinos, C. (2005). Naturalistic hermeneutics. Cambridge: Cambridge University Press.

Mantzavinos, C. (Ed.). (2009). Philosophy of the social sciences. Cambridge: Cambridge University Press. in press.

Mantzavinos, C., North, D. C., \& Shariq, S. (2004). Learning, institutions, and economic performance. Perspectives on Politics, 2, 75-84.

Marshall, A. (1920). Principles of economics (8th ed.). London: McMillan.

Mueller, D. (2003). Public choice III. Cambridge: Cambridge University Press.

Osterfeld, D. (1989). Radical federalism: Responsiveness, conflict and efficiency. In G. Brennan \& L. Lomasky (Eds.), Politics and process (pp. 149-173). Cambridge: Cambridge University Press.

Qian, Y., \& Weingast, B. (1997). Federalism as a commitment to preserve market incentives. Journal of Economic Perspectives, 11, 83-92.

Rawls, J. (1971). A theory of justice. Cambridge: Harvard University Press.

Ribstein, L., \& Kobayashi, B. (Eds.). (2007). The economics of federalism. Aldershot: Edward Elgar. Riker, W. (1964). Federalism: Origin, operation, and significance. Boston: Little Brown and Company. Shapiro, D. (1995). Federalism: A dialogue. Illinois: Northwestern University Press.

Stigler, G. J., \& Becker, G. S. (1977). De Gustibus Non Est Disputandum. American Economic Review, 67, 76-90.

Tiebout, C. M. (1956). A pure theory of local expenditures. Journal of Political Economy, 64, 416-424. 
Vanberg, V., \& Kerber, W. (1994). Institutional competition among jurisdictions: An evolutionary approach. Constitutional Political Economy, 5(2), 193-219.

Vaubel, R. (1995). The centralization of Western Europe. London: Institute of Economic Affairs.

Walzer, M. (1990). The communitarian critique of liberalism. Political Theory, 18(1), 6-23.

Weingast, B. (1995). The economic role of political institutions: Market perserving federalism and economic development. Journal of Law, Economics, and Organization, 11, 1-31. 